\title{
Use of Oral Bisphosphonates by Older Adults with Fractures and Impaired Renal Function
}

\author{
Cheryl A Sadowski, Tara Spencer, and Nese Yuksel
}

\begin{abstract}
Background: The manufacturers of oral bisphosphonates (alendronate, risedronate) recommend avoiding use of these drugs in patients with renal impairment. However, many patients who have osteoporosis or who are at risk of fracture are elderly and may have renal impairment. This situation poses a quandary for clinicians in deciding how best to manage osteoporosis in this high-risk population.
\end{abstract}

Objective: To synthesize published evidence regarding the use and safety of oral bisphosphonates for patients with impaired renal function.

Methods: The following databases were searched up to October 2010: PubMed, MEDLINE, Embase, the Cochrane Library, and International Pharmaceutical Abstracts. The following key words and terms were used for the searches: bisphosphonates, alendronate, risedronate, Fosamax, Actonel, "renal failure", "renal insufficiency", "chronic kidney disease", and "end-stage renal disease". The manufacturers of Fosamax and Actonel were asked to provide information about use of their products in patients with renal impairment, including unpublished pharmacokinetic studies or reports of adverse drug events.

Results: The search yielded 2 post hoc analyses of safety data, 1 case-control study, 1 case series, 4 retrospective chart analyses, and 2 prospective studies. According to these publications, numerous patients with decreased renal function have received bisphosphonates and have experienced improvement in bone mineral density and/or reduction in risk of fractures, with no increase in adverse effects. Increased renal damage occurred in some individuals with underlying renal disorders, as described in case reports.

Conclusions: Although the literature is limited, there is evidence that alendronate and risedronate are well tolerated and effective when used by individuals with renal impairment. Further research is required to confirm the benefits and risks of using these medications in patients with renal impairment.

Key words: osteoporosis, renal insufficiency, chronic kidney disease, bisphosphonate, alendronate, risedronate

Can J Hosp Pharm 2011;64(1):36-41

\section{RÉSUMÉ}

Contexte : Les fabricants de bisphosphonates oraux (alendronate, risédronate) recommandent d'éviter l'emploi de ces médicaments chez les patients souffrant d'insuffisance rénale. Cependant, de nombreux patients souffrant d'ostéoporose ou qui sont à risque de fracture sont des personnes âgées qui pourraient souffrir d'insuffisance rénale. Cette situation est un véritable dilemme pour les cliniciens qui doivent décider de la meilleure conduite à tenir pour traiter l'ostéoporose chez cette population à risque élevé.

Objectif : Mettre en lumière les données probantes publiées sur l'emploi et l'innocuité des bisphosphonates oraux chez les patients souffrant d'insuffisance rénale.

Méthodes : Les bases de données suivantes ont été examinées : PubMed, MEDLINE, Embase, Bibliothèque Cochrane et International Pharmaceutical Abstracts. Les mots clés et termes suivants ont été utilisés pour les recherches : bisphosphonates, alendronate, risédronate, Actonel, Fosamax, "insuffisance rénale ", " maladie rénale chronique " et " insuffisance rénale terminale ». Les recherches dans les bases de données ont été faites jusqu'en octobre 2010. On a demandé aux fabricants d'Actonel et de Fosamax de fournir de l'information sur l'utilisation de leurs produits chez les patients atteints d'insuffisance rénale, y compris les résultats d'études pharmacocinétiques inédites ou les rapports d'événements indésirables liés aux médicaments.

Résultats : La recherche a révélé deux analyses a posteriori de données sur l'innocuité, une étude cas-témoin, une série de cas, quatre analyses rétrospectives de dossiers médicaux et deux études prospectives. D'après ces documents, de nombreux patients atteints d'insuffisance rénale ont reçu des bisphosphonates et présenté un accroissement de leur densité minérale osseuse ou une réduction du risque de fractures, sans augmentation des effets indésirables. On a observé une augmentation des lésions rénales chez certains patients présentant des troubles rénaux sous-jacents, comme décrit dans plusieurs observations cliniques.

Conclusions : Bien que la documentation soit limitée, des données probantes montrent que l'alendronate et le risédronate sont bien tolérés et efficaces dans les cas d'insuffisance rénale. Des recherches plus approfondies sont nécessaires pour confirmer les bienfaits et les risques de ces médicaments chez les personnes souffrant d'insuffisance rénale.

Mots clés : ostéoporose, insuffisance rénale, maladie rénale chronique, bisphosphonate, alendronate, risédronate

[Traduction par l'éditeur] 


\section{INTRODUCTION}

$\mathrm{R}$ enal impairment presents a significant challenge in the treatment of osteoporosis. Guidelines for the management of osteoporosis have recommended bisphosphonates as first-line therapy for the prevention of osteoporotic fractures. ${ }^{1,2}$ Alendronate and risedronate are widely used because they are well tolerated and have been shown to reduce the incidence of both hip and vertebral fractures. ${ }^{3}$ However, bisphosphonates are cleared exclusively by the kidneys and are not recommended for patients with significant renal impairment. More specifically, alendronate is not recommended for patients with creatinine clearance $(\mathrm{CrCl})$ less than $35 \mathrm{~mL} / \mathrm{min},{ }^{4}$ and risedronate is not recommended for those with $\mathrm{CrCl}$ less than $30 \mathrm{~mL} / \mathrm{min} .^{5}$ These restrictions reflect the exclusion criteria that have been used in clinical studies of these medications, which in turn arose from previous concerns about renal failure occurring secondary to intravenously administered bisphosphonates. ${ }^{6}$ Of note, there are no precautions for use of etidronate in patients with renal impairment. ${ }^{7}$

Postmenopausal women with renal dysfunction are left with the following options for osteoporosis therapy: calcitonin, raloxifene, hormone therapy, denosumab, and teriparatide. ${ }^{1-3}$ However, there are drawbacks to all of these therapies. Denosumab is the only drug (other than alendronate and risedronate) that has been shown to reduce hip fractures among patients with osteoporosis. In the Women's Health Initiative, hormone therapy reduced the risk of hip fractures among women without diagnosed osteoporosis (primary prevention), ${ }^{8}$ but the use of hormone therapy for osteoporosis is currently limited to postmenopausal women who are also being treated for vasomotor symptoms. ${ }^{2}$ In addition, risks associated with these therapies, such as thromboembolism or breast cancer, may deter patients and clinicians from long-term use. ${ }^{1-3,9}$

Many older adults with osteoporosis also have age-related impairment of renal function. ${ }^{10-13}$ One study, which used the Third National Health Assessment and Nutritional Examination Survey (NHANES III) data set for men and women 20 years of age and older, found that $85 \%$ of women and $58 \%$ of men with osteoporosis could be classified as having chronic kidney disease. ${ }^{14}$ According to the guidelines of the US National Kidney Foundation, chronic kidney disease is defined as glomerular filtration rate (GFR) less than $60 \mathrm{~mL} .{ }^{15}$ Chronic kidney disease is staged as a 5-stage model, where stage 1 is the least severe and stage 5 the most severe (GFR $15 \mathrm{~mL} / \mathrm{min}$ or below).

Bisphosphonates are cleared exclusively by the kidneys, through glomerular filtration and active tubular secretion, so these agents accumulate during renal failure. ${ }^{16,17}$ Pharmacokinetic studies with risedronate have shown a significant decline in plasma clearance and an increase in area under the curve when $\mathrm{CrCl}$ drops from 120 to $20 \mathrm{~mL} / \mathrm{min} .{ }^{17}$ An increase in serum concentrations of bisphosphonates could theoretically lead to an increase in retention of these drugs in bone. ${ }^{16-18}$ This concern stems from early animal studies in which administration of etidronate resulted in osteomalacia in mature, healthy dogs. ${ }^{19} \mathrm{~A}$ decline or halt in bone remodelling could lead to further damage to the bone microarchitecture and could compromise bone strength. ${ }^{18}$ Animal data have also suggested that bisphosphonates increase microdamage, microcracks, and tissue mineralization, all of which may be detrimental to underlying bone strength in patients with renal failure. ${ }^{18}$ In addition to osteoporosis, patients with chronic kidney disease commonly exhibit a spectrum of other bone diseases, ${ }^{15,18,20}$ such as adynamic bone disease, making them more vulnerable to the effects of bisphosphonates. ${ }^{15}$ According to the clinical practice guidelines for bone metabolism and disease in chronic kidney disease set out by the National Kidney Foundation Disease Outcomes Quality Initiative, adynamic bone disease is now common in association with stage 5 chronic kidney disease. This increase may result in part from aggressive treatment with calcium-based phosphate binders and vitamin $\mathrm{D}$, leading to oversuppression of parathyroid hormone and significant slowing of bone turnover. ${ }^{15}$ Additional cause for concern in this population has been driven by early reports of acute renal failure with IV bisphosphonates. However, this concern has been largely discounted by other investigators, who suggested that rapid infusion rates (e.g., less than $15 \mathrm{~min}$ for zoledronic acid) were likely to blame. ${ }^{18,21}$ Finally, there is a relative lack of data on the safety and efficacy of bisphosphonates in patients with chronic kidney disease.

Given the prevalence of concurrent renal impairment and osteoporosis, clinicians will be challenged in making decisions about the use of bisphosphonates, a clinical quandary that will become more common as the population ages. The purpose of this study was to synthesize current evidence about the efficacy and safety of oral bisphosphonates for patients with impaired renal function.

\section{METHODS}

In this review, the available evidence on the use of first-line oral bisphosphonates in renal failure was applied to the decisionmaking process for patients with osteoporosis and renal impairment. The literature was searched for published reports describing the use of bisphosphonates in patients with renal failure. The following bibliographic databases were searched for all published articles up to October 2010: PubMed, Embase, MEDLINE, the Cochrane library and International Pharmaceutical Abstracts. Key words and terms used in this search were bisphosphonates, alendronate, risedronate, Fosamax ${ }^{\circledR}$, Actonel ${ }^{\circledR}$, "renal failure", "renal insufficiency", "chronic kidney disease", and "end-stage renal disease". The search was limited to articles published in English. In addition, the manufacturers of Fosamax (Merck Frosst) and Actonel (Procter \& Gamble) were contacted for 
information on the use of these products in renal failure, specifically for any unpublished information on efficacy and safety in renal impairment.

\section{RESULTS}

The available literature identified by the search included 2 post hoc analyses of safety data from several clinical trials involving the use of risedronate and alendronate..$^{22,23}$ In addition, 1 case-control study, ${ }^{24} 1$ case series, ${ }^{25}$ and 4 chart reviews ${ }^{26-29}$ were also found, along with 2 prospective studies on the use of bisphosphonates in patients close to requiring or already receiving dialysis. ${ }^{30,31}$ In this review article, we discuss the use of oral bisphosphonates available in Canada for the treatment of osteoporosis in patients with renal impairment.

The 2 secondary safety analyses provided the strongest evidence. The first study was a secondary analysis of the Fracture Intervention Trial (FIT) with alendronate. ${ }^{22}$ The FIT was a 3year randomized controlled trial involving 6458 women $55-80$ years of age. In total, 581 (9.0\%) of the women enrolled in the study had a normal serum creatinine level but reduced renal function $(\mathrm{CrCl}<45 \mathrm{~mL} / \mathrm{min})$. Despite the increased risk of fracture because of underlying renal impairment, the reduction in fracture risk with alendronate therapy in this group was similar to that for women with normal renal function. In addition, there were significant improvements in bone mineral density (BMD) at the spine and the hip, irrespective of renal function. More importantly, there was no difference in adverse events between the 2 groups. The authors concluded that among women with osteoporosis who had reduced GFR but normal serum creatinine level, alendronate was safe and effective for fracture reduction over a period of 4 years. The limitations of the trial included a failure to exclude women with $\mathrm{CrCl}$ below the manufacturer's recommended cutoff for alendronate; as a result, nearly $10 \%$ of the participants had $\mathrm{CrCl}$ less then $35 \mathrm{~mL} / \mathrm{min}$.

Miller and others ${ }^{23}$ completed a post hoc analysis of 9 published clinical trials of risedronate to study the effects of renal function on the safety and efficacy of this drug. In total, 4500 patients received placebo and 4496 received risedronate. The average trial duration was 2 years, and some trials lasted 3 years. The pooled analysis examined a total of 301 patients with $\mathrm{CrCl}$ below the manufacturer's cutoff of $30 \mathrm{~mL} / \mathrm{min}$ who had received risedronate. Some of the trials included patients up to 100 years of age. Only one study included men, and that study focused on corticosteroid-induced osteoporosis. ${ }^{32}$ Risedronate improved $\mathrm{BMD}$ and reduced vertebral fractures, regardless of renal function. Among patients with $\mathrm{CrCl}$ below $30 \mathrm{~mL} / \mathrm{min}$, those taking risedronate had increases in lumbar spine BMD of $4.23 \%$ (standard error [SE] 1.82\%), whereas placebo was associated with a decrease in BMD (-1.37\%, SE 1.72\%). Adverse event profiles were similar in all subgroups. The authors concluded that risedronate $5 \mathrm{mg}$ daily for up to 3 years was safe and effective in patients with $\mathrm{CrCl}$ as low as $15-30 \mathrm{~mL} / \mathrm{min}^{23}$ The results of this study suggested that elderly women are not at increased risk of adverse events with risedronate. However, all trials in the analysis used daily bisphosphonate dosing rather than once-weekly dosing, the approach more commonly used today. ${ }^{33}$ It is unknown how the use of once-weekly dosing would influence these results.

A case-control study explored the effect of alendronate on bone mass in elderly male veterans with reduced renal function. ${ }^{24}$ Patients were included if they had received at least 6 months of alendronate therapy, had undergone 2 BMD tests, and had a GFR of $35 \mathrm{~mL} / \mathrm{min}$ or less, as determined by the modification of diet in renal disease (MDRD) equation. ${ }^{34}$ Among the 15 case patients, the mean age was 82 years and the mean GFR $26 \mathrm{~mL} / \mathrm{min}$. Among the 15 controls, the mean age was 62 years and the mean GFR $70 \mathrm{~mL} / \mathrm{min}$. Both cases and controls had used alendronate for about 35 months. BMD comparisons for lumbar spine, femur, and radius showed no significant differences between cases and controls. In addition, there was no difference in the type or frequency of adverse events. ${ }^{24}$ Although the small sample was a limitation, this was one of the few studies that examined outcomes for a combination of efficacy and safety measures. In addition, the study focused on men, a group frequently excluded from bisphosphonate studies.

A recently published case series described 13 patients with stage $2-4$ chronic kidney disease who also had a diagnosis of osteoporosis or osteopenia. The patients had been taking bisphosphonates for at least 4 months (some for as long as 5 years). In all 13 patients, adynamic bone disease had developed, as confirmed by histologic examination. ${ }^{29}$ Although the results of this study do not imply that bisphosphonates are unsafe, they do highlight the importance of appropriate diagnosis and assessment of patients with chronic kidney disease who may have other bone diseases. Treatment of osteoporosis or osteopenia may lead to a delay in correctly diagnosing and treating other bone diseases and may exacerbate the underlying bone disorder.

The literature search revealed 3 chart reviews of bisphosphonate use in elderly patients. ${ }^{26-28}$ The purpose of the study by Bernett and others ${ }^{26}$ was to determine the compliance of long-term-care health care providers with alendronate prescribing guidelines, in relation to renal insufficiency and upper gastrointestinal disorders. A total of 905 female nursing home residents were included in the analysis, but serum creatinine had not been documented for 348 (38.5\%) of them. To be eligible for inclusion, patients had to be taking either alendronate $(n=$ $445)$ or calcitonin-salmon nasal $(n=460)$. Of the 267 patients receiving alendronate whose $\mathrm{CrCl}$ had been documented, 137 (51.3\%) had $\mathrm{CrCl}$ below $35 \mathrm{~mL} / \mathrm{min}$. Tolerability and adverse events were not reported. The authors concluded that 
prescribers were not considering patient profiles and safety data when initiating treatment for osteoporosis.

Another retrospective analysis was performed at a renal services clinic in a hospital in Belfast, United Kingdom, to assess prescribing patterns for bisphosphonates in patients with low estimated GFR. This study included 595 patients, of whom 327 (55\%) were male. The patients' charts were reviewed to determine whether they were being treated for osteoporosis. ${ }^{27} \mathrm{~A}$ total of 32 patients $(5 \%)$ had a prescription for a bisphosphonate, and 13 (41\%) of these had GFR below $30 \mathrm{~mL} / \mathrm{min} ; 2$ of these latter patients were undergoing dialysis. Although the study described the use of bisphosphonates in patients with renal impairment, no information on BMD, fractures, or drug safety was provided. ${ }^{27} \mathrm{~A}$ third chart review, conducted in a seniors clinic affiliated with the University of Colorado Hospital, was designed to evaluate changes in $\mathrm{CrCl}$ and adverse events related to oral bisphosphonate therapy. ${ }^{28} \mathrm{~A}$ total of 181 patients receiving oral bisphosphonates (mean duration of therapy 22.3 months) were included in the study, of whom 31 had severe kidney impairment $(\mathrm{CrCl}<35 \mathrm{~mL} / \mathrm{min})$. Six $(19 \%)$ of the 31 patients with severe kidney impairment but just 18 (12\%) of the 150 patients without renal impairment experienced an adverse event. However, there was no difference in discontinuation rates between the groups. One additional chart review, presented only as an abstract, was conducted to determine adverse events associated with bisphosphonate therapy in patients with renal impairment. ${ }^{25}$ Of the 124 women included in the study, 16 (12.9\%) had $\mathrm{CrCl}$ below $35 \mathrm{~mL} / \mathrm{min}$. No serious adverse events were reported for any of these patients.

Together, these studies ${ }^{25-28}$ suggest that some individuals, especially elderly patients with renal impairment, continue to receive bisphosphonates despite manufacturers' recommendations to the contrary. Although these studies indicate that bisphosphonates are well tolerated, they had several limitations, such as small sample size and lack of documentation in medical records.

Our literature search yielded 2 studies involving patients with confirmed advanced renal impairment, ${ }^{30,31}$ both of which described renal function as a function of serum creatinine only (i.e., $\mathrm{CrCl}$ and GFR were not calculated). In the first study, Sharma and others ${ }^{30}$ evaluated use of alendronate in 70 predialysis patients with uremia and moderate to severe renal impairment. Among these patients, the mean serum creatinine at study entry was $3.45 \mathrm{mg} / \mathrm{dL}(304 \mu \mathrm{mol} / \mathrm{L})$. At baseline, BMD testing showed that 46 of the 70 patients had osteoporosis, and 16 had osteopenia. However, all patients were being treated with alendronate, regardless of BMD. After 6 months, repeat BMD testing (available for only 8 of the patients) showed an increase in BMD of the spine, but no changes in BMD of the femoral neck or distal forearm. Adverse events were rare: 4 patients experienced gastrointestinal adverse effects and 1 patient had hypercalcemia requiring admission to hospital. Wetmore and other $^{31}$ randomly assigned 31 hemodialysis patients with normal bone density to receive either alendronate $40 \mathrm{mg}$ weekly or placebo for 6 weeks. BMD of the hip and lumbar spine was preserved over a 6-month follow-up period, with few adverse events reported. The BMD in placebo-treated patients decreased at the hip $(p=0.05)$ but remained stable at the lumbar spine. Three patients reported gastric discomfort with the first dose of alendronate, but all patients tolerated subsequent doses. Of note, both of these studies ${ }^{30,31}$ intentionally enrolled patients with significant renal impairment. However, both had brief follow-up periods. Overall, their results shed some light on empiric dosing of bisphosphonates for patients with renal impairment and suggest that these patients may experience few adverse events. Although some authors have advocated lower doses of bisphosphonates for patients with renal impairment, ${ }^{35}$ there is little evidence to support such adjustments. ${ }^{6}$ Additional research in this population over longer study periods may help in determining the utility of empiric dose reduction and the long-term consequences of using bisphosphonates for patients with renal impairment.

One further consideration in dosing relates to the method of estimating renal function. The MDRD equation has become increasingly popular for this purpose. Burkiewicz and others ${ }^{36}$ recently undertook a retrospective analysis of 157 patients undergoing treatment in a US osteoporosis clinic to identify any discordance between the MDRD and Cockcroft-Gault equations. They showed that use of the MDRD equation, rather than the Cockcroft-Gault equation, may have led to overestimations of renal function, which would have led to bisphosphonate treatment for $8.5 \%$ of patients with contraindications for this medication. The authors suggested using both estimates of renal function, in addition to clinical judgment, when prescribing bisphosphonates.

Although previous studies have supported the efficacy and safety of bisphosphonates for patients with impaired renal function, much of the evidence of renal toxicity comes from data for IV bisphosphonates. ${ }^{37-39}$ Oral bisphosphonates, when used properly, appear to be well tolerated, with minimal effects on renal function. ${ }^{40} \mathrm{~A}$ recently published case report described the development of proteinuria and acute renal failure in a 61year-old man after initiation of oral alendronate. ${ }^{41}$ Notably, the patient had nephrotic syndrome with focal segmental glomerulosclerosis, which had been responding well to steroid therapy, and his $\mathrm{CrCl}$ was $64 \mathrm{~mL} / \mathrm{min}$. The alendronate was started to prevent steroid-induced osteoporosis, but within 2 weeks there had been a dramatic increase in urinary protein, and the patient was in acute pre-renal failure. The patient underwent 6 cycles of hemodialysis and 4 cycles of apheresis. After 40 days of treatment, the patient's renal function returned to baseline. Another case report described a man who experienced focal segmental glomerulosclerosis after receiving oral alendronate 
$35 \mathrm{mg}$ weekly. ${ }^{42}$ However, the patient had other complicating factors, having recently undergone liver transplantation after development of liver cirrhosis because of hepatitis. His estimated GFR was $23 \mathrm{~mL} / \mathrm{min}$, and he had bilateral edema of the lower extremities at the time of initiation of alendronate. In another case, acute renal failure occurred 1 month after initiation of alendronate (10 $\mathrm{mg}$ daily) in a woman with multiple myeloma, who had normal baseline renal function. Her renal failure resolved after the alendronate was discontinued. ${ }^{43}$ Although these cases highlight adverse events associated with use of bisphosphonates, all of the patients appeared to have significant comorbidities, including evidence of renal disease.

\section{DISCUSSION}

The scenario of an elderly patient with a history of osteoporosis or fractures and renal impairment represents a clinical quandary commonly faced by practitioners treating osteoporosis in our aging population. The manufacturers of oral bisphosphonates have specified that their products should be used in patients with $\mathrm{CrCl}$ of at least 30 or $35 \mathrm{~mL} / \mathrm{min}$ (depending on the particular product). The recently updated guidelines continue to support the use of bisphosphonates as first-line therapy for osteoporosis and prevention of fractures. ${ }^{2}$

Whether or not clinicians choose to adhere to the product monographs and avoid using bisphosphonates for patients with renal impairment, a number of other interventions should be implemented for osteoporosis. ${ }^{44}$ For example, prevention of falls, nutritional interventions, restriction of phosphates, and use of other pharmacologic agents should be considered.

In this review, we have synthesized the evidence for the efficacy and safety of oral bisphosphonates when used for patients who do not meet the manufacturers' recommended thresholds for renal function. The evidence reviewed here highlights the fact that oral bisphosphonates have been used by, and have provided clinical benefit to, elderly patients with renal impairment with no increase in adverse events. However, there are limitations to the research published to date. Many studies had a small sample size or short duration of treatment, or they were based on retrospective analysis of patients' medical charts. The strongest evidence comes from studies involving women with postmenopausal osteoporosis. Research regarding osteoporosis in men (especially men with renal impairment) is lacking. ${ }^{45}$ Some studies categorized the patients' renal function according to different equations, and others used serum creatinine rather than $\mathrm{CrCl}$ as an indicator of renal function. A few reports of patients with significant underlying chronic diseases have shown that in some cases, oral bisphosphonates may themselves lead to acute renal impairment. Of note, these patients had underlying renal disease or other significant comorbidity.
The findings of the current review indicate a critical need for longer-term, prospective studies of the use of bisphosphonates in patients with renal impairment.

\section{References}

1. Brown JP, Josse RG. 2002 clinical practice guidelines for the diagnosis and management of osteoporosis in Canada. CMAJ 2002;167(10 Suppl): S1-S34.

2. Papaioannou A, Morin S, Cheung AM, Atkinson S, Brown JP, Feldman S, et al. 2010 clinical practice guidelines for the diagnosis and management of osteoporosis in Canada: summary. CMAJ 2010;182(17):1864-1873.

3. Mayes SL. Review of postmenopausal osteoporosis pharmacotherapy. Nutr Clin Pract 2007;22(3):276-285.

4. Alendronate (Fosamax®) [product monograph]. Kirkland (QC): Merck Frosst Canada, Ltd; 2010.

5. Actonel ${ }^{\circledR}$ risedronate sodium (as the hemi-pentahydrate) [product monograph]. Toronto (ON): Procter \& Gamble Pharmaceuticals Canada, Inc; 2008.

6. Courtney AE, Maxwell AP. Chronic kidney disease and bisphosphonate treatment: are prescribing guidelines unnecessarily restrictive? Postgrad Med J 2009;85(1004):327-330.

7. Etidronate sodium and calcium carbonate (Didrocal $\left.{ }^{\circ}\right)$ [product monograph]. Toronto (ON): Warner Chilcott Canada Co; 2010.

8. Cauley JA, Robbins J, Chen Z, Cummings SR, Jackson RD, LaCroix AZ, et al.; Women's Health Initiative Investigators. Effects of estrogen plus progestin on risk of fracture and bone mineral density: the Women's Health Initiative randomized trial. JAMA 2003;290(13):1729-1738.

9. Rossouw JE, Anderson GL, Prentice RL, LaCroix AZ, Kooperberg C, Stefanick ML, et al.; Writing Group for the Women's Health Initiative Investigators. Risks and benefits of estrogen plus progestin in healthy postmenopausal women: principal results from the Women's Health Initiative randomized controlled trial. JAMA 2002;288(3):321-333.

10. Lindeman RD, Tobin J, Shock NW. Longitudinal studies on the rate of decline in renal function with age. J Am Geriatr Soc 1985;33(4):278-285.

11. Lindeman RD. Assessment of renal function in the old. Special considerations. Clin Lab Med 1993;13(1):269-277.

12. Ishida K, Ishida $H$, Narita $M$, Sairenchi T, Saito Y, Fukutomi H, et al. Factors affecting renal function in 119985 adults over three years. QJMed 2001;94(10):541-550.

13. Ensrud KE, Palermo L, Black DM, Cauley J, Jergas M, Orwoll ES, et al. Hip and calcaneal bone loss increase with advancing age: longitudinal results from the study of osteoporotic fractures. J Bone Miner Res 1995; 10(11):1778-1787.

14. Klawansky S, Komaroff E, Cavanaugh PF Jr, Mitchell DY, Gordon MJ, Connelly JE, et al. Relationship between age, renal function and bone mineral density in the US population. Osteoporos Int 2003;14(7):570-576.

15. K/DOQI clinical practice guidelines for bone metabolism and disease in chronic kidney disease. Am J Kidney Dis 2003;42(4 Suppl 3):S1-S201.

16. Lin JH. Bisphosphonates: a review of their pharmacokinetic properties. Bone 1996;18(2):75-85.

17. Mitchell DY, St Peter JV, Eusebio RA, Pallone KA, Kelly SC, Russell DA, et al. Effect of renal function on risedronate pharmacokinetics after a single oral dose. Br J Clin Pharmacol 2000;49(3):215-222.

18. Miller PD. Is there a role for bisphosphonates in chronic kidney disease? Semin Dial 2007;20(3):186-190.

19. Lenehan TM, Balligand M, Nunamaker DM, Wood FE Jr. Effect of EHDP on fracture healing in dogs. J Orthop Res 1985;3(4):499-507.

20. Gal-Moscovici A, Sprague SM. Osteoporosis and chronic kidney disease. Semin Dial 2007;20(5):423-430.

21. Rodd C. Bisphosphonates in dialysis and transplantation patients: efficacy and safety issues. Perit Dial Int 2001;21 Suppl 3:S256-S260.

22. Jamal SA, Bauer DC, Ensrud KE, Cauley JA, Hochberg M, Ishani A, et al. Alendronate treatment in women with normal to severely impaired renal function: an analysis of the Fracture Intervention Trial. J Bone Miner Res 2007;22(4):503-508. 
23. Miller PD, Roux C, Boonen S, Barton IP, Dunlap LE, Burgio DE. Safety and efficacy of risedronate in patients with age-related reduced renal function as estimated by the Cockcroft and Gault method: a pooled analysis of nine clinical trials. J Bone Miner Res 2005;20(12):2105-2115.

24. Hansen KE, Hofmann RM, Drake RK, Argall TR, Bier HA, Grigg KT, et al. An exploratory analysis of alendronate in older men with low glomerular filtration rate. J Aging Pharmacother 2006;13(2):21-33.

25. Lewiecki EM, Rudolph LA. Oral bisphosphonate for treatment of osteoporosis in elderly patients with impaired renal function.J Bone Miner Res 2002;17 Suppl 1:SU335.

26. Bernett GB, Feldman S, Martin H, Smith BC, Raineri BD. An opportunity for medication risk reduction, healthcare provider collaboration, and improved patient care: a retrospective analysis of osteoporosis management. J Am Med Dir Assoc 2003;4(6):329-336.

27. Courtney AE, Leonard N, McClosky MC, Smyth JS, Maxwell AP. Bisphosphonate prescribing in chronic kidney disease. $J R$ Coll Physicians Edinb 2009;39(1):4-9.

28. Linnebur SA, Milchak JL. Assessment of oral bisphosphonate use in elderly patients with varying degrees of kidney function. Am J Geriatr Pharmacother 2004:2(4):213-218.

29. Amerling R, Harbord NB, Pullman J, Feinfeld DA. Bisphosphonate use in chronic kidney disease: association with adynamic bone disease in a bone histology series. Blood Purif 2010;29(3):293-299.

30. Sharma RK, Kaushal R, Gupta A, Gupta S, Gulati S, Sharma AP. Use of oral alendronate for treatment of osteoporosis in pre-dialysis chronic renal failure population [abstract]. Nephrol Dial Transplant 2003;18 Suppl 4:413.

31. Wetmore JB, Benet LZ, Kleinstuck D, Frassetto L. Effects of short-term alendronate on bone mineral density in haemodialysis patients. Nephrology (Carlton) 2005;10(4):393-939.

32. Wallach S, Cohen S, Reid DM, Hughes RA, Hosking DJ, Laan RF, et al. Effects of risedronate treatment on bone density and vertebral fracture in patients on corticosteroid therapy. Calcif Tissue Int 2000;67(4):277-285.

33. Bisphosphonates in osteoporosis: an analysis focusing on drug claims by seniors, 2001 to 2007. Ottawa (ON): Canadian Institute for Health Information; 2010 [cited 2010 Oct 27]. Available from: http:// secure.cihi.ca/cihiweb/products/npduis_aib_bisphosphonates2009_e.pdf

34. Levey AS, Bosch JP, Lewis JB, Greene T, Rogers N, Roth D. A more accurate method to estimate glomerular filtration rate from serum creatinine: a new prediction equation. Modification of Diet in Renal Disease Study Group. Ann Intern Med 1999;130(6):461-470.

35. Miller PD. Treatment of osteoporosis in chronic kidney disease and end-stage renal disease. Curr Osteoporos Rep 2005;3(1):5-12.

36. Burkiewicz JS, Griffin BL, Komperda KE. Bisphosphonates in renal insufficiency: comparison of estimated glomerular filtration rate methods. J Am Geriatr Soc 2009;57(12):2351-2353.
37. Strampel W, Emkey R, Civitelli R. Safety considerations with bisphosphonates for the treatment of osteoporosis. Drug Saf 2007;30(9):755-763.

38. Perazella MA, Markowitz GS. Bisphosphonate nephrotoxicity. Kidney Int 2008;74(11):1385-1393.

39. Toussaint ND, Elder GJ, Kerr PG. Bisphosphonates in chronic kidney disease; balancing potential benefits and adverse effects on bone and soft tissue. Clin J Am Soc Nephrol 2009;4(1):221-233.

40. Yanik B, Bavbek N, Yanik T, Inegöl I, Kanbay M, Turgut FH, et al. The effect of alendronate, risedronate, and raloxifene on renal functions, based on the Cockcroft and Gault method, in postmenopausal women. Ren Fail 2007;29(4):471-476.

41. Miura N, Mizuno N, Aoyama R, Kitagawa W, Yamada H, Nishikawa K, et al. Massive proteinuria and acute renal failure after oral bisphosphonate (alendronate) administration in a patient with focal segmental glomerulosclerosis. Clin Exp Nephrol 2009;13(1):85-98.

42. Pascual J, Torrealba J, Myers J, Tome S, Samaniego M, Musat A, et al. Collapsing focal segmental glomerulosclerosis in a liver transplant recipient on alendronate. Osteoporos Int 2007;18(10):1435-1438.

43. Zazgornik J, Grafinger P, Biesenbach G, Hubmann R, Fridrik M. Acute renal failure and alendronate. Nephrol Dial Transplant 1997;12(12):2797-2798.

44. Gordon PL, Frassetto LA. Management of osteoporosis in CKD stages 3 to 5. Am J Kidney Dis 2010;55(5):941-956.

45. Rahmani P, Morin S. Prevention of osteoporosis-related fractures among postmenopausal women and older men. CMAJ 2009;181(11):815-820.

Cheryl A Sadowski, BSc(Pharm), PharmD, is with the Faculty of Pharmacy and Pharmaceutical Sciences, University of Alberta, Edmonton, Alberta.

Tara Spencer, BSc, BScPharm, is with the Pharmacy Department, University of Alberta Hospital, Edmonton, Alberta.

Nese Yuksel, BScPharm, PharmD, is with the Faculty of Pharmacy and Pharmaceutical Sciences, University of Alberta, Edmonton, Alberta.

\section{Address correspondence to:}

Dr Cheryl A Sadowski

Faculty of Pharmacy and Pharmaceutical Sciences

3126 Dentistry/Pharmacy Centre

University of Alberta

Edmonton AB T6G 2N8

e-mail: csadowski@pharmacy.ualberta.ca 